\title{
Paramagnetic pyrrole-based semiconductor molecular material
}

\author{
Mathieu Lazerges $\cdot$ Kathleen Isabelle Chane-Ching • \\ Salah Aeiyach • Saloua Chelli • Brigitte Pepin-Donat • \\ Martial Billon • Christian Lombard • François Maurel • \\ Mohamed Jouini
}

Published online: 17 June 2008

(C) Springer-Verlag 2008

Erratum to: J Solid State Electrochem

DOI 10.1007/s10008-008-0549-8

Unfortunately, the spelling of the author's name of Brigitte Pepin-Donat was incorrect.

The online version of the original article can be found at http://dx.doi. org/10.1007/s10008-008-0549-8.

Contribution to the Fall Meeting of the European Materials Research, Society, Symposium D: 9th International Symposium on the,

Electrochemical-Chemical Reactivity of Metastable Materials,

Warsaw, 17th-21st September, 2007.

K. I. Chane-Ching $\cdot$ S. Aeiyach $\cdot$ S. Chelli $\cdot$ F. Maurel $\cdot$

M. Jouini $(\bowtie)$

ITODYS, Université Denis Diderot CNRS UMR 7086,

1 rue Guy de la Brosse,

75005 Paris, France

e-mail: jouini@univ-paris-diderot.fr

B. Pepin-Donat $\cdot$ M. Billon $\cdot$ C. Lombard

DRFMC/SPrAM,

Université Joseph Fourier CEA CNRS UMR 5819,

17 Avenue des Martyrs,

38054 Grenoble, France

M. Lazerges

Laboratoire Génie Analytique, EA 4131 CNAM,

292 rue Saint Martin,

75003 Paris, France 